\title{
Stress erhöht die Infarktsterblichkeit langfristig
}

\begin{abstract}
Stress triggert Herzinfarkte. Darüber hinaus erhöht emotionale Belastung die Mortalität nach dem Infarkt bis zu zwei Jahre lang. Vor allem jüngere Patienten sind betroffen.
\end{abstract}

- Patienten, die in den vier Wochen vor einem Herzinfarkt eine mittelhohe bis hohe Stressbelastung angeben, haben auch in den zwei Jahren nach dem Infarkt eine höhere Sterblichkeit als Patienten mit wenig Stress. „Bisher waren wir davon ausgegangen, dass hohe Stressbelastung einen Infarkt auslösen kann. Unsere Befunde zeigen jetzt, dass Stress auch langfristig die Prognose nach dem Infarkt verschlechtert. Wir Ärzte sollten dem Stress als Risikofaktor unserer Herzpatienten mehr Beachtung schenken“, erklärte Studienautorin S. Arnold vom St. Luke's Mid America Heart Institute in Kansas City.

Die Autoren hatten 4200 Patienten eines Herzinfarktregisters ausgewertet, die innerhalb der ersten drei Tage nach Krankenhauseinweisung nach ihrer psychosozialen Belastung in den vier Wochen vor dem Ereignis befragt worden waren. Es zeigte sich, dass die $40 \%$ der Patienten mit der höchsten Stressbelastung ein signifikant erhöhtes Sterberisiko hatten ( $13 \%$ vs. $8,6 \%)$ im Ver- gleich zu den 60\% der Patienten mit geringerer Stressbelastung.

Besonders bemerkenswert: die gestressten Herzinfarktpatienten waren im Schnitt fünf Jahre jünger als die Patienten mit wenig Stress, und sie wiesen weniger prognostisch ungünstige Risikofaktoren auf. Laut GRACE-Score hatten sie eigentlich eine relativ günstige Prognose.

Patienten mit hohem Stresslevel waren überwiegend Frauen mit hohem Blutdruck, aber geringer Bildung, wenig sozialer Unterstützung und finanziellen Sorgen.

$\mathrm{DE}$.

\section{Vorchristliche Atherosklerose}

\section{Arterienverkalkungen bei ägyptischen Mumien}

\begin{abstract}
Atherosklerose kann endgültig nicht nur als Folge modernen Lebensstils beschrieben werden. Schon die alten Ägypter zeigten Gefäßverkalkungen. Der bislang älteste dokumentierte KHK-Fall: Eine Prinzessin, die vor rund 3500 Jahren starb.
\end{abstract}

- Noch bevor es im heutigen Ägypten zur Revolution gegen den Pharao der Neuzeit gekommen war, hatte ein Team um den Nuklearkardiologen Dr. Grego-

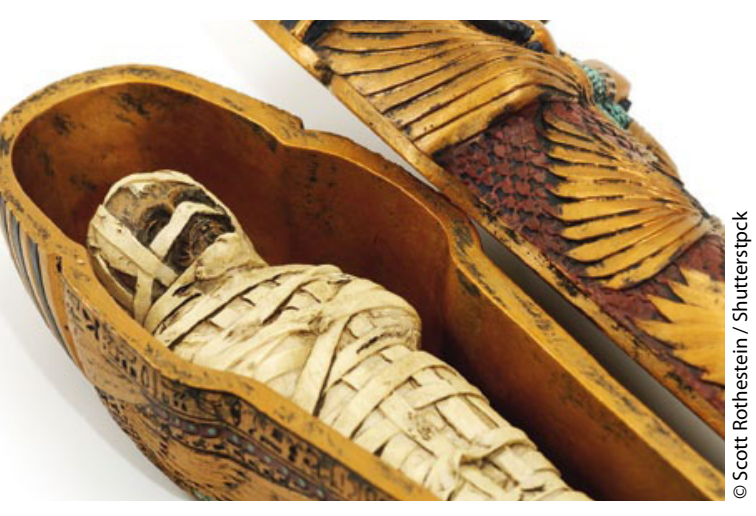

Vom Koronarkalk ins Grab gebracht? ry S. Thomas von der Universität Irvine in Kalifornien Gelegenheit, 52 ägyptische Mumien in einem GanzkörperMehrschicht-CT-Scanner zu untersuchen. Die Forscher fahndeten nach Gefäßverkalkungen. Bei 43 der Mumien ließen sich Gefäße identifizieren, bei 20 Mumien war das Herz erhalten.

Wie gesund lebten die alten Ägypter? Die Ägypter, denen eine Mumienbegräbnis zuteil wurde, gehörten zu einer elitären Oberschicht. Vermutlich ließen sie sich bedienen und legten kaum selbst Hand an, als es galt, Steine zu Pyramiden zu türmen. Auf der anderen Seite kannte die ägyptische Oberschicht weder die klimatisierte Mittelklasse-Limousine noch das Fastfood-Restaurant, und TV und Computer gab es auch noch nicht. Ägyptologen bestätigen, dass sich die Oberschicht im alten Ägypten gesünder ernährt und mehr bewegt hat als der moderne Mensch.

Vor diesem Hintergrund überrascht der Fund von atherosklerotischen Lä- sionen bei 20 der 43 Mumien. Verkalkungen wurden nachgewiesen in Karotiden, in der Aorta, den Koronararterien sowie in der A. subclavia, der A. iliaca., der A. femoralis, der A. poplitea und der A. tibialis. Die 20 Mumien mit Atherosklerose waren bei ihrem Tod älter (im Durchschnitt etwa 45 Jahre) als diejenigen ohne Atherosklerose (33 Jahre).

Besonders spektakulär ist der Nachweis von Koronarverkalkungen bei zwei Mumien. Die älteste bis dato bekannte Koronarpatientin ist demzufolge eine ägyptische Prinzessin, die 1580-1540 vor Christus lebte und schätzungsweise mit Mitte 40 verstarb. Bei dem anderen Kororarpatienten handelte es sich um einen Mann, der einige Jahrhunderte später im Alter von Mitte 50 verstarb.

Fazit: Schon die alten Ägypter litten unter den gleichen Erkrankungen des Herz-Kreislauf-Systems, die heute weltweit zur häufigsten Todesursache avanciert sind. Die genetische Prädisposition scheint eine größere Rolle zu spielen als gemeinhin angenommen wird. $\quad D_{\text {. }}$ 